\title{
QUALITY MANAGEMENT IN TEXTILE ENTERPRISES IN HO CHI MINH CITY, VIETNAM
}

\author{
Nguyen Thi Phuong Dung ${ }^{1}$, Tran Thi Phuong Thuy ${ }^{2}$ \\ ${ }^{1}$ Foreign Trade University Hochiminh city campus, 15 D5 Street 25 Ward Binh Thanh District, \\ HochiminhCity, 084, Vietnam, nguyenthiphuongdung.cs2@ftu.edu.vn, (0962823487) \\ ${ }^{2}$ Foreign Trade University Hochiminh city campus, 15 D5 Street 25 Ward Binh Thanh District, \\ HochiminhCity, 084, Vietnam tranthiphuongthuy.cs2@ftu.edu.vn, (0908934282)
}

\begin{abstract}
Product quality is one of the factors determining the success or failure of businesses, especially in the textile and garment industry. In 2017, Vietnam's textile products were exported to more than 180 countries reaching 25.91 billion USD, an increase of $8.7 \%$, accounting for $14 \%$ of total export turnover of Vietnam. Textile growth rate in the period 2013-2017 reached more than 8\% per year. With the significant development, Vietnam become one of the countries with the fastest growth rate of textile export turnover in the world. Therefore, product quality management issues need to be examined. The paper uses analytical and integrated research methods to clarify the actual situation of quality management activities in some textile enterprises in Ho Chi Minh city, Vietnam. The paper also provides some remarks for recommending appropriate solutions to some textile enterprises in Ho Chi Minh city, Vietnam.
\end{abstract}

\section{Keywords}

Textile enterprises, quality management, Hochiminh city

\section{JEL Classification}

C52

DOI: https://doi.org/10.14311/bit.2019.01.01

Editorial information: journal Business \& IT, ISSN 2570-7434, CreativeCommons license (c) (1) published by CTU in Prague, 2019, http://bit.fsv.cvut.cz/ 


\section{Introduction}

In the market mechanism to be able to stand firm, survive and develop, businesses must prioritize product quality first. Product quality determines the success or failure of the business. Enterprises with better product quality and reasonable prices in line with customers' needs will be able to win in competition and vice versa, it will be very difficult to stand firm in the market.

For the textile industry - one of the foundations of industrialization and modernization of the country, the issue of improving product quality is extremely important. When Vietnam became the 150th member of the World Trade Organization (WTO), the domestic textile and garment industry also had to innovate in designs and improve product quality to meet the tastes of customers in the domestic and foreign markets. However, the current status of the textile and garment industry is too old and outdated compared to the world. Therefore, the product quality of the textile industry is difficult to fully meet the requirements of product quality as the international market. Textile and garment export turnover of enterprises in Ho Chi Minh City accounts for about $20 \%$ of the total textile and garment export turnover of the whole country. This shows the importance of Ho Chi Minh city's textile and garment industry to Vietnam's textile and garment industry. Therefore, the authors selected to study the topic "Quality management in textile enterprises in Ho Chi Minh city, Vietnam".

\section{Theoretical basis}

According to ISO 9000: 2015, the process of applying quality management system includes four steps:

\section{A. Quality planning}

According to ISO 9000: 2015, "Quality planning is a part of quality management, focusing on establishing quality targets and regulating necessary operational processes and relevant resources to realize objectives of quality".

Quality planning allows enterprises to orient quality development for the whole organization in a unified way, exploiting and using resources more effectively in the long term, contributing to reducing costs for quality. In addition, planning helps organizations actively penetrate and expand markets, create conditions to improve competitiveness in the market, create new culture, a fundamental transformation of the quality management methods of organization.

The main content of quality planning is to establish general quality goals, and quality policy; customer identification, needs and characteristics of customer needs; planning characteristics of products that meet customer needs; process planning capable of creating product characteristics; transfer planning results to the operational department. When planning quality, organizations need to answer the following questions: Who is the customer? What do they expect when buying products? Is it true that they are expected? It continues to be what they expect? How much do they pay for the product? How much do they need to buy and when?.

\section{B. Quality checking}

According to ISO 9000: 2015, quality inspection is the activity of monitoring, measuring, collecting quality information to assess the implementation of the objectives and tasks of quality planning proposed in all processes, all activities and results of performance of quality indicators in practice compared to the requirements and standards set. There are many bases to be used in quality control: System of standards, quality standards of products and services; Requirements showing design drawings; Terms specified in sales contracts, orders; System of procedures and procedures; Requirements on technology and labor discipline. The main task of quality control is to carry out the 
following tasks: Evaluate the quality performance and determine the actual level of quality achieved in the enterprise; Compare the actual quality with the plan to detect errors and evaluate the differences in the economic - technical and social aspects; Identify effective quality assurance activities and their results; Discovering unfulfilled goals, unresolved issues; Check the design process and product design quality; Checking production conditions, machinery and equipment; Check raw materials input; Check each production stage and the quality of semi-finished products in each stage; Final product quality inspection; Check the preservation, transportation and quality of service activities before and after sales. There are many testing methods such as visual inspection, laboratory, and expert interview. Products can be tested entirely or in the form of sampling.

\section{Quality assurance}

According to ISO 9000: 2015, quality assurance is planned and systematic activities conducted to demonstrate that consumers are satisfied with the quality requirements. Quality assurance is a part of QC that focuses on providing confidence that the requirements will be fulfilled. The function of quality assurance includes: creating and implementing a quality control policy, quality assurance policy with all standards in accordance with the requirements of the State, industry and customers; planning and step by step applying the quality management system; evaluation, inspection and quality control; collect, analyze and process quality data.

\section{Quality improvement}

According to ISO 9000:2015, quality improvement is part of quality management that focuses on improving performance. Quality requirements may relate to any aspect such as efficiency, performance and traceability. Some methods can be used such as Kaizen and PDCA cycle.

Kaizen is a philosophical approach published by Masaaki Imai, the author of the book named "Kaizen: The Key to Japan's Competitive Success" in 1986. Kaizen has 3 basic philosophies: Human resources are valuable assets of the company; Processes must be improved step by step; Improvements are based on qualitative assessments of process performance. According to Imai, Kaizen means continuous improvement with the participation of all people, leaders and employees to eliminate obstacles and difficulties in the continuous improvement process. This continuous improvement can be divided into six steps: Standardization (Begins with the process of making a specific activity repeatable and organized), Measurement (Check whether the process is effective using data that can be quantified in terms of completion time, number of hours to spend...), Comparison (Compare measurement results with requirements. Does that process save time? Does it take too much time? Does it match the expected results?), Innovation (Looking for new, better ways to do the same job or achieve the same result. Search for smarter, more effective ways that reach the same goal that can increase productivity), Standardization (Create another similar process for new, more efficient operations) and Repeat (Return to step 1 and start again).

The PDCA cycle, also known as the Deming circle, is a model of continuous improvement by American Walter Shewhart, physicist, engineer and statistician. PDCA circle consists of four main elements: Plan, Do, Check, Act. The first element is Plan to improve product quality, including 9 steps as follows. Step 1 is to identify the process: start, end and things to do. Step 2 is to describe the process: make a list of the main tasks that need to be done, the sequence of steps, the participants to implement, equipment, environmental conditions, measures to perform work, raw materials needed. Step 3 is to describe the participants: customers inside and outside the company, suppliers; Step 4 is to determine customer expectations: what customers want, when and where. Step 5 is to determine the data on the process performance, which data needs to be collected to understand the process more 
clearly. Step 6 is to describe the problems related to the process; for example: can't meet customer expectations, big fluctuations, long waiting times..... Step 7 is to identify the main causes of problems, and the impact of these causes on the performance of the process. Step 8 is to develop solutions, change implementation to improve the process, assess changes or solutions to solve the causes. Step 9 is to choose one or more feasible and effective solutions. The second element is Do, including 2 steps: step 1: carry out the test plan to evaluate whether the test plan is effective or not; step 2: determine how to measure the test plan in solving problems. The third element is Check, consisting of 3 steps: step 1: evaluate the results of the test plan; step 2: determine whether the test plan will bring better results; step 3: identify other testing solutions that need to be done if needed. And the last element is Act, including 4 steps: step 1: choose the best plan; step 2: implement the plan; step 3: conduct standardization of the plan; step 4: set up a process to monitor and check process performance.

\section{Methodology}

By analyzing and synthesizing methods, the paper presents the reality of quality management activities at a number of textile enterprises in Ho Chi Minh City and gives some comments as well as suggestions to improve the task.

\section{Results}

A. The actual situation of quality management activities in some textile enterprises in Ho Chi Minh city, Vietnam

> Quality management activities at Thanh Cong Textile Garment - Investment - Trading Joint Stock Company (TCG)

First, quality planning and design

Quality policy of the company includes regulations on application of quality management system according to ISO 9001: 2015; ISO quality system of the company is trained, understood and responsible in the work of each member; product quality is constantly improved, ensuring uniformity and stability; All products manufactured by the company in the workplace are in accordance with the requirements of social responsibility and working conditions of Vietnamese law and international conventions.

Design is the stage of specifying customer requirements into specific quality and technical regulations of products. The quality of design is assessed by the company through the ability to quantify the requirements of the value of use in an optimal way, facilitating the manufacture of products to satisfy customers' needs with the maximum cost. To ensure the quality of the design, the company has divided the design process into the following stages: planning and project design, technical design, design quality inspection.

Second, product quality inspection

With the motto "doing right from the beginning", determined to create a non-defect product environment, the product quality inspection is focused on the company. The company's quality control facility is using statistical methods to make decisions. Currently, the company is using both statistical testing methods: process inspection: done in all production stages, acceptance sampling: it is done in raw materials and final products.

The company's inspection includes all types of activities such as: testing and measuring to determine if the standard is met. Most of the company's inspection work is done by qualified test personnel. Each item is analyzed by the company to determine the extent to which it is necessary to check and propose an appropriate inspection sequence for it. Inspectors are equipped with appropriate testing equipment and are instructed how to handle inappropriate products. During the inspection, the 
company established and maintained an accurate recording system. The test results are fully recorded in the prescribed forms.

Third, product quality assurance

The production process is one of the decisive steps for product quality assurance. Therefore, when setting up the production plan, the company always facilitates the quality management activities to be conducted smoothly according to a certain process. The purpose of managing the company's production process is not to eliminate bad and bad quality products that have just been produced but must prevent bad products from appearing in the production process; on the other hand, preventing bad products not only based on the Quality Checking Department, or watching quality inspection methods is the main method to remove waste products and products.

\section{$>$ Quality management activities at the Company 28}

First, product quality planning

Product quality objectives to implement and maintain ISO 9001: 2015 constantly improve and improve efficiency; achieved revenue growth of $220 \%$; reduce the rate of discarded products to $0.05 \%$; the rate of products to be repaired at the workshop is not more than $6 \%$.

Quality policy includes the company committed to textile products in accordance with customer requirements, everything must be done right from the start, good quality, competitive prices, on-time delivery, supply With sufficient resources for the quality system, this policy is understood, implemented and maintained by all members of the company for the benefit of customers and themselves.

The company conducts quality planning through taking orders, responding to customer requirements and resource planning to ensure orders can be executed. The company has divided the planning and design process into the following stages: design planning, technical design and production, design quality inspection before production.

Second, inspection and quality assurance

Inspection is done for raw materials, semi-finished products and finished products before warehousing.

For raw materials: Inspection documents include: technical documents provided by customers, a Table of instructions for using raw materials or samples of objects provided by customers, invoices for goods importation.

Material inspection: Based on the warehousing vouchers, based on the guiding documents to compare the signs and symbols on the cloth and label of the litchi and compare the materials and colors of the fabric with the specimen or table Use of customer materials.

Testing the color: Based on the customer manual of raw material use. Based on in-kind products as a basis to compare and determine the fabric surface of the material.

For auxiliary materials: careful consideration of documents and procedures for warehousing based on the method of packing of customers to check each type of auxiliary materials of imported goods to determine whether they are suitable or inappropriate. Products.

Product inspection: based on technical standards documents of goods codes, guidelines for using NPLs, sample products. Based on the product inspection process in the process. Check the size, texture on the product, color, fabric material and compare sample products approved by customers.

Inspection work is also carried out on product packaging. Based on technical documents, packaging documentation, packaging methods to check. 


\section{Quality management activities at Nha Be Garment Corporation (NBC)}

First, quality planning

Quality policy of Nha Be Garment Company is "The company ensures that products manufactured at the company meet all safety, legal and quality requirements". Quality policies are disseminated to all members of the company.

NBC's quality objectives include reducing the rate of finished product recycling to less than $5 \%$; no customer complaints; strive to achieve the total revenue of 2017 of $\$ 850$ million.

Customer requirements for product design and development are presented in writing by the Department of Planning and Import-Export (Market-Import-Export Plan) and transferred to the Company Design Department. Based on the ideas and requirements of customers, the Design Department of the Company carries out the design, selecting the right materials and colors. After that, the Design Department transferred the design file to the Engineering Technology Department. The department must verify the feasibility of the product design and development.

The output of design and development must be approved by the Board of Directors, Head of Engineering Technology Department and customers before being put into production. Before deploying the production, the Engineering Technology Department will receive the information on Arabic, samples, technical documents, original sample products... and together with the Engineering Technology Department to carry out the sample products for Customers browse before production. At the same time, the Enterprise Management Department, and the Line manager will build the line design, assign labor in accordance with that product. In the process of production deployment, deployment technique guides workers to each stage according to the production process along with the coordination control of the quality checking department and line management.

Second, inspection and quality assurance

Material inspection: Depending on the requirements of the customer, the material inspection staff applies inspection according to the customer's request. If the customer does not require it, all imported materials will be tested on a 4-point system. All materials must be $100 \%$ tested before cutting.

Cutting quality inspection: Quality control in the cutting stage is carried out from the fabric spreading area until the finished semi-finished products are prepared for sewing.

Checking the sewing stage: quality checking person passes inspection; Methods of sensory examination; $100 \%$ check. Depending on the complexity of the product, the quality checking person is divided into clusters so that the inspection can be carried out quickly and prevent errors from happening massively.

Checking the final product:

For boxed products, the final inspection will be done in two stages. Stage 1: Perform inspection after ironing and before packaging, it is necessary to carry out the inspection before packing because if the batch of inspection products is removed, it must be checked again, then it will not be removed. Containers to avoid damage to the packaging materials. The inspection criteria during this period are similar to those in the end-of-line inspection and post-ironing inspection. Stage 2: Check after packing.

For suspended goods: will be checked after completion. The inspection criteria include all the above requirements (after ironing, nylon bags, hangers, hanging labels...) 


\section{B. Evaluation}

\section{$>$ Advantages}

First, the management of the company has become stable. The system of documents in the quality system has been fully developed and revised many times to improve. The work is fast, tight, scientific, creating a quite lively quality environment throughout the company.

Second, the quality policy is easy to understand, reflecting the innovation in quality awareness towards the satisfaction of customer needs and the company's leadership.

Third, the company has trained a highly qualified management team, experienced management, dynamic, enthusiastic, in work, with high determination, so it is proactive and innovates its organizational structure in the right direction with high management effectiveness, and contributes to the improvement of quality.

Fourth, the company is aware of the importance of production workers. It has focused and quality training for all production workers. So far, all production workers have a relative awareness of product quality and a greater sense of responsibility in their work.

Fifth, the quality management and improvement of machinery and equipment are also done quite well. The company has expanded and upgraded warehouses, finished products to better preserve product quality, gradually replacing imported raw material to reduce their fluctuation in production. At the same time, the company has invested and renewed many types of automatic machinery and equipment so the quality has been constantly improved.

Sixth, the quality inspection and supervision work is strictly conducted from the input production stage to the final product to be stored, so it has been discovered, and prevented quickly the adverse issues affecting product quality.

\section{$>$ Disadvantages}

First, although the company has changed its perception of product quality, the management awareness approach is still largely limited in production.

Second, the issue of quality control of products and measures to improve product quality are inconsistent, only focusing on raising the awareness of departments, factories and workers, but no policies encourage and promote creativity to improve the quality of their products.

Third, machinery and equipment have been invested but not synchronized. Some new machines are bought, the rest are mainly bought in the form of transferring old machinery from foreign companies. Therefore, the quality of machinery sometimes does not guarantee the quality and is outdated compared to the development of science and technology in the world.

Fourth, the work of product quality inspection, although it has been strengthened, has not fully utilized the features of the current management method. The inspection department is out of production too much, while workers directly producing products have not fully utilized their advantages, still working passively and often have a stressful relationship with the inspection department.

Fifth, the new quality training is only at a relative level, not yet achieving high results. The workers just stop at perceiving, receiving and implementing instructions from the top down mechanically without creativity to find solutions in all situations.

Sixth, enterprises have not implemented the quality improvement by applying tools such as PDCA or Kaizen philosophy. This leads to the quality management according to the routine, not any innovations which can be created by workers to help the production process smoothly and reduce low quality products. 


\section{Conclusion and discussion}

In conclusion, textile enterprises in Hochiminh city, Vietnam face both advantages and disadvantages in quality management. In order to improve the quality management activities, textile enterprises in Ho Chi Minh city, Vietnam need to implement some solutions as follows:

First, innovating awareness, improving professional qualifications for employees in the enterprise. Innovation awareness whether in the form or how to do it has the purpose of equipping the necessary knowledge and skills to help employees perform their functions and tasks in a self-conscious way. Thereby, employees will contribute practically to improving the quality of products and services they create, contributing to improving the quality management system in the enterprise. In addition to the general awareness of equipment for all officials and employees, depending on the professional position and functions and functions, each individual and department should equip their own knowledge and skills accordingly.

Senior leaders need to be equipped with more complete and integrated knowledge. Senior leaders must provide documents on the commitment to deploy and develop quality management systems and continually improve their effectiveness. Senior leaders must ensure that the quality objectives are set for each department and relevant ministries at the organization level. Quality, measurable goals and must be consistent with policies and plans including commitment to continuous improvement. Quality objectives must include content that meets the requirements of the product. When setting quality goals, management considers the current and future needs of the business market organization. This review will serve as a basis for establishing the quality objectives that resources in the enterprise are capable of achieving. This will make the quality management system of the enterprise be applied in a seamless way. In order to avoid the fact that the theory is far removed from reality, the set target is not feasible.

There is a need for unity among administrators to reasonably arrange the resources of the company and the department in which they are focusing on:

- The organization promotes the process of establishing, implementing and maintaining a quality management system as required by ISO 9001-2015.

- Implement standardization activities: measurement, inspection, testing and necessary standards on culture, expertise, foreign languages and professional skills for employees.

- Disseminate to all employees the specific knowledge of product quality, quality management system, responsibility of each individual and department in implementing policies and quality objectives. It is decided by the management of the enterprise and approved by the whole staff of the enterprise, about the benefits of each person associated with the implementation of the integrated quality of the relationship, a must have between businesses and investors, with service providers, with stakeholders, give employees a sense of mutual respect for the common goal of the business.

- Establishing quality clubs, quality groups in enterprises, quality groups can spread new knowledge about quality management according to ISO 9001:2015, creating conditions and giving environment exchanging, learning from each other, helping to quickly grasp the requirements of ISO 9000. Clubs need to be organized appropriately to arouse enthusiasm, promote ideas that bring benefits to improve the quality of products.

- Invite consultants on Total Quality Management (Total Quality Management - TQM), Kaizen, PDCA to teach and talk through meetings and seminars.

- Encourage employees in the enterprise to participate in the innovation movement, promote new initiatives to improve the efficiency of production activities organized by the consulting association.

Second, implementing policies to encourage material and spiritual employees. 
In order to encourage the establishment of self-awareness about the implementation, application, maintenance and transformation of the expanded quality management system, the company should devise clear system of reward and punishment. So this is an effective measure, not only to encourage the departments and individuals to do well according to the quality requirements of the quality system, promote creativity and potential in the each individual employee but also immediately prevents intentional or negligent acts of violating the requirements.

In order for the bonus to stimulate workers in production to comply with the requirements set by the system, the company should reconsider the bonus and punishment factor based on the importance of each part that affects directly. Next to the quality of products as well as the responsibility of each level in the application of ISO 9000 quality management system. Content of the standard vote is as follows:

- Standard A, B, C by month:

* Type A:

+ Good completion of assigned tasks.

+ Ensuring sufficient working days in the regime in the month (if sick leave, unpaid leave for 1 day, all categories will be dropped). Private leave for 2 days in a month still reaches type $A$.

+ Strictly abide by all rules and regulations of the company and workshops; does not violate any defects.

* Type B:

+ Good completion of all assigned tasks.

+ Ensure full 18 working days in the month.

+ Violation of a defect.

+ Holidays must have a good reason, there must be an application for leave and a day's notice for the company to arrange for someone to replace.

* Type C:

+ Workdays reach from 8 to 18 days in a month.

+ Violation of 2 or more defects.

+ A day off without any reason.

- Criteria for advanced labor vote

+ Good completion of all assigned tasks.

+ Meeting the standard of grade A voting pots for 12 months / year.

+ No violation of any defects.

+ Dynamic, creative at work.

+ Being respected and voted by everyone.

- Excellent labor standards:

+ Achieving advanced labor standards in the production and business process.

+ Many contributions to all movement activities.

+ Always achieve outstanding achievements.

+ Really exemplary is recognized by everyone in the company.

+ Being respected and voted by everyone.

One of the measures to promote quality up is quality improvement. Under current conditions, innovation is an important method to improve labor productivity. The company should have rewarding regimes for initiatives and topics to promote technical progress, improve and rationalize production to bring economic efficiency, contributing to improving workers' lives. The company also needs to set bonus levels for initiatives. By doing this well, it will encourage people to work properly as defined in 
the procedures as well as comply with the approved requirements in the system and promote creativity, innovation and quality improvement.

However, there is still certain limitation which is expected to be improved in the future research. Due to the constraints of time and budget, the sample is relatively small with three textile enterprises among 10 enterprises with the largest export turnover in Ho Chi Minh City, Vietnam. This definitely limits the level to which the results can be generalized.

\section{References}

[1] Bureau of Quality Testing. (2016). TCVN ISO 9001:2015.

[2] NBC. (2009). Standard operating procedure.

[3] NBC. (2009). Quality Manual.

[4] The Corporation 28. (2010). Operating procedures for quality management of garment products.

[5] The Corporation 28. (2010). Quality Manual.

[6] TCG .(2009). Guidelines for implementing garment quality management activities.

[7] Evans, J. R. and Lindsay, W. M. (2008). Managing for quality and performance excellence. 9th edn. USA: Cengage Learning.

[8] Imai, M. (1986). Kaizen, the key to Japan's competitive success. New York, Random House Business Division. 